\title{
Spark Plasma Sintering of Fuel Cermets for Nuclear Reactor Applications
}

\section{MRS Fall Meeting}

Yang Zhong

Robert O'Brien

Steven Howe

Nathan Jerred

Kristopher Schwinn

Laura Sudderth

Joshua Hundley

The INL is a

U.S. Department of Energy

National Laboratory

operated by

Battelle Energy Alliance

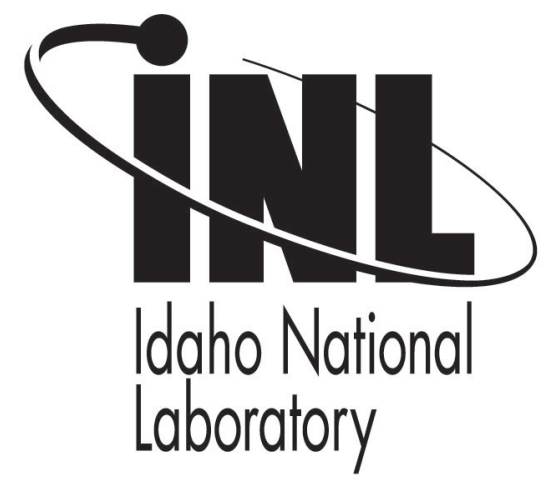

\section{November 2011}

This is a preprint of a paper intended for publication in a journal or proceedings. Since changes may be made before publication, this preprint should not be cited or reproduced without permission of the author. This document was prepared as an account of work sponsored by an agency of the United States Government. Neither the United States Government nor any agency thereof, or any of their employees, makes any warranty, expressed or implied, or assumes any legal liability or responsibility for any third party's use, or the results of such use, of any information, apparatus, product or process disclosed in this report, or represents that its use by such third party would not infringe privately owned rights. The views expressed in this paper are not necessarily those of the United States Government or the sponsoring agency. 


\section{Spark Plasma Sintering of Fuel Cermets for Nuclear Reactor Applications}

Yang Zhong ${ }^{1,2}$, Robert C. O’Brien ${ }^{1}$, Steven D. Howe ${ }^{1}$, Nathan D. Jerred ${ }^{1}$, Kristopher Schwinn ${ }^{1}$, Laura Sudderth $^{1}$ and Joshua Hundley ${ }^{1}$

${ }^{1}$ Center for Space Nuclear Research, Idaho National Laboratory, ID 83415, U.S.A.

${ }^{2}$ Department of Chemical, Materials and Biomolecular Engineering, University of Connecticut, CT 06269, U.S.A.

\section{ABSTRACT}

The feasibility of the fabrication of tungsten based nuclear fuel cermets via Spark Plasma Sintering (SPS) is investigated in this work. $\mathrm{CeO}_{2}$ is used to simulate fuel loadings of $\mathrm{UO}_{2}$ or Mixed-Oxide (MOX) fuels within tungsten-based cermets due to the similar properties of these materials. This study shows that after a short time sintering, greater than $90 \%$ density can be achieved, which is suitable to possess good strength as well as the ability to contain fission products. The mechanical properties and the densities of the samples are also investigated as functions of the applied pressures during the sintering.

\section{INTRODUCTION}

The Center for Space Nuclear Research (CSNR), located in Idaho Falls, ID and operated by Universities Space Research Association (USRA) and Idaho National Laboratory (INL), with a wealth of experience in research and development of advanced space nuclear systems, including power and propulsion systems, and radioisotope power generators, has been very active in creating opportunities for university researchers to collaborate with their counterparts at NASA, INL and other DOE labs. CSNR has devoted extensive effort on the fabrication of tungsten based nuclear cermets for nuclear reactors for space exploration application. During the 2011 summer fellowship program of CSNR, tungsten based nuclear cermets have been fabricated via Spark Plasma Sintering (SPS) process. The tungsten based nuclear cermets fabricated by SPS will not only be applicable for the space exploration application but also for the ground based nuclear reactors. This paper focuses on the cermets for ground based nuclear reactor applications.

Nuclear energy contributes $\sim 20 \%$ of the total electricity consumed in the United States ${ }^{[1]}$. However, the energy production process, i.e., nuclear fission, produces high level of radioactive fission products. Under some extreme conditions, these fission products may disperse into the atmosphere, such as the recent events in Fukishima, Japan. This revealed a need for a high temperature fuel form that will not melt down from decay heat after a loss of coolant accident. Furthermore, the fuel material should contain the fission products from dispersion during a combination of accidental high temperature excursions and steam/hydrogen explosions. W-UO $\mathrm{U}_{2}$ cermet fuels are of particular interest these days due to its ability to contain fission products when increased operational safety and security are demanded. The traditional fabrication techniques (including hot isostatic pressing or hipping, pressure-less sintering, etc), which require very high processing temperature and long sintering time, had been utilized in the GE 
710 program and ANL program for nuclear thermal propulsion $(\mathrm{NTP})^{[2]}$. These fabrication techniques lead to several problems, as elaborated below. (i) The high processing temperatures typically lead to the dissociation of $\mathrm{UO}_{2}$ during sintering. (ii) Grain growth at high temperature with long sintering time can degrade the mechanical properties of the cermets, impede the densification process and decrease the interface/surface area of the metal and oxide, resulting in slower heat conduction.

SPS is a promising process to fabricate the fuel cermets with dramatically decreased average processing temperature and shortened sintering time ${ }^{[3,4]}$. A study on the feasibility of the fabrication of tungsten based nuclear cermets via SPS and the effects of the sintering parameters on the densities and the properties of the cermets will be of great importance for the future applications of nuclear fuel cermets. Within this study the sintering of tungsten using SPS was firstly investigated. Secondly, with the understanding of the sintering mechanisms for pure tungsten, the sintering of the mixture of tungsten and cerium oxide was studied for a specific volumetric ratio of ceramic to metal matrix materials. Finally, we studied the effects of the applied external pressure during the sintering on the densities and the mechanical properties of the cermets.

\section{EXPERIMENT}

$\mathrm{CeO}_{2}$, which has similar thermodynamic properties with $\mathrm{UO}_{2}$ (e.g., melting points, Gibbs free energy), was selected as a surrogate material. Tungsten powder with the average particle size of $\sim 10 \mu \mathrm{m}$ and $\mathrm{CeO}_{2}$ with the average particle size of $\sim 50 \mu \mathrm{m}$ were utilized in this study. The different sizes of $\mathrm{CeO}_{2}$ and $\mathrm{W}$ can enhance the packing density and allow small tungsten particles to fill the voids between the $\mathrm{CeO}_{2}$ particles. The powders were mixed with the ratio of $50 \mathrm{vol} \% \mathrm{~W}$ and $50 \mathrm{vol} \% \mathrm{CeO}_{2}$. The powder mixtures were loaded into a graphite die and were pressed by two graphite punches on the two ends, as shown in Figure 1. Grafoil was inserted between the powder mixture and graphite die/punches to serve as the diffusion barrier between the cermets and graphite. The powders were pre-pressed by uni-axial pressing using a small hydraulic pressure to avoid the leakage during the sintering process.

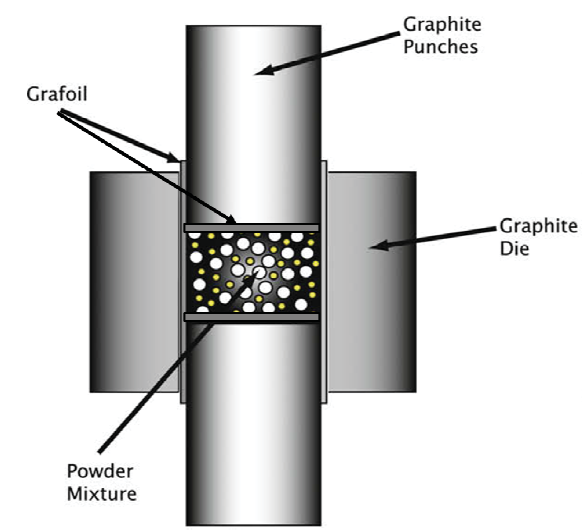

Figure 1. The schematic picture of the punches and die assembly containing mixed $\mathrm{CeO}_{2}$ and $\mathrm{W}$ powder [4].

In the SPS process, the power mixture is heated by Joule heating, which results from passing an electric current through the powder matrix. It is reported that the densification behaviors of the powder is strongly affected by the current pulse modulation ${ }^{[5]}$ and the materials 
transport for sintering can be enhanced by the application of external pressure ${ }^{[6]}$. To study the effects of the pressure on the densities and the properties of the cermets, three different pressures (37, 45 and $53 \mathrm{MPa}$ ) are selected in the experiment. The pressure is applied by the hydraulic rams in the SPS furnace. Figure 2 shows the temperature and pressure profiles designed for the sintering process. The temperature is set to increase to $600{ }^{\circ} \mathrm{C}$ in $8 \mathrm{~min}$. Then, the temperature is set to dwell at $600{ }^{\circ} \mathrm{C}$ for $2 \mathrm{~min}$ because that below $600{ }^{\circ} \mathrm{C}$ the temperature is controlled by limiting the output current, while close to and above $600{ }^{\circ} \mathrm{C}$ the temperature is adjusted from the reading of the optical pyrometer instead of the current limit. The holding at low temperature can also avoid the overshoot of the temperature at higher temperatures. The temperature will then reach $1500{ }^{\circ} \mathrm{C}$ and hold at $1500{ }^{\circ} \mathrm{C}$ for $20 \mathrm{~min}$. For the sintering of pure tungsten powder, pressure profile (1) is employed. It is noted that the sintering temperature $\left(1500^{\circ} \mathrm{C}\right)$ is below 50 $\%$ of the melting point of tungsten.

The diamonds plates with the diamond grain sizes of $(9,6,3)$ micron are utilized in the grinding process and the polycrystalline diamond suspensions with the diamond grain sizes of $(6$, $3,0.5)$ micron are selected for the polishing of the cermets.

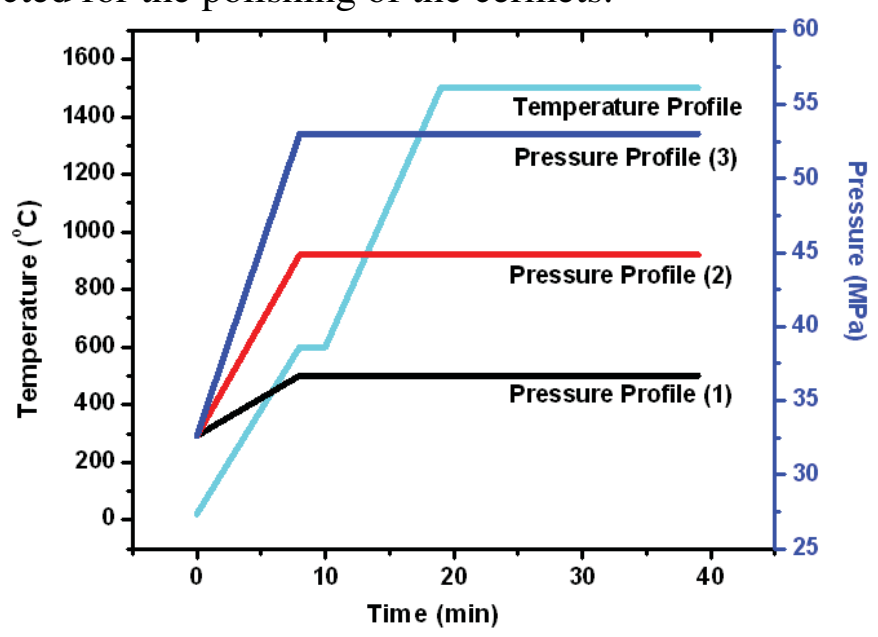

Figure 2. The temperature and pressure profiles for the SPS sintering processes.

\section{RESULTS and DISCUSSION}

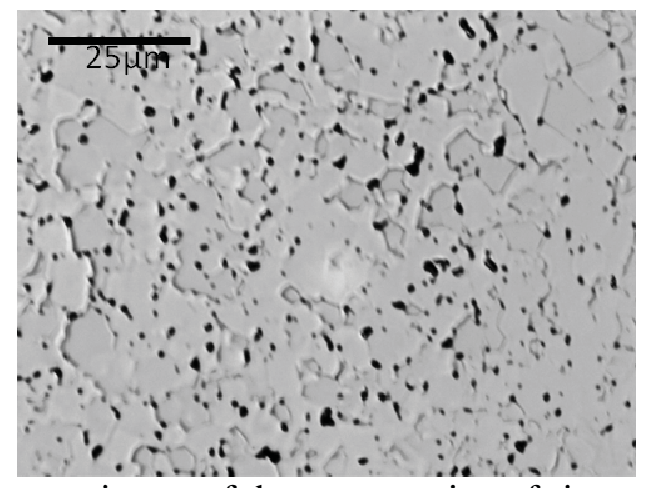

Figure 3. The optical microscope image of the cross section of sintered $\mathrm{W}$ after surface finishing. 
The tungsten powder is sintered using the pressure profile 1 . The microstructure of the sample is shown in Figure 3. Several interesting points can be found from the figure. (i) The average grain size of tungsten is found to be around $10 \mu \mathrm{m}$, indicating there is little or no growth of the tungsten powder during the sintering process owing to the short sintering time and low sintering temperature. (ii) The sample density is calculated to be $90 \%$ based on the imaging analysis of the optical micrograph. Compared with the conventional pressure-less sintering of W with the same particle size $(10 \mu \mathrm{m})$, which shows that the sample can only achieve $\sim 75 \%$ density after $8 \mathrm{~h}$ sintering at $1500{ }^{\circ} \mathrm{C}^{[7]}$, the SPS shows a great advantage of achieving higher density in significantly decreased sintering time. (iii) Another interesting finding is that the pores are located in the grain boundaries instead of inside the tungsten grains. This provides a great advantage for the fabrication of the nuclear cermets, because the pores in the grain boundary may provide the space to contain gaseous fission products. However, these site may also give rise to mechanical weaknesses which must be evaluated through mechanical testing(iv) Compared with a previous study on the SPS sintering of $\mathrm{W}-\mathrm{CeO}_{2}$ cermets conducted at the CSNR which demonstrated that $93.6 \%$ density was achieved using tungsten with a particle size of $3-6 \mu \mathrm{m}$ after SPS sintering at $1500{ }^{\circ} \mathrm{C}^{[4]}$, the effect of the particle size can be clearly seen. The particles with smaller size are easier to achieve higher density in the bulk matrix.

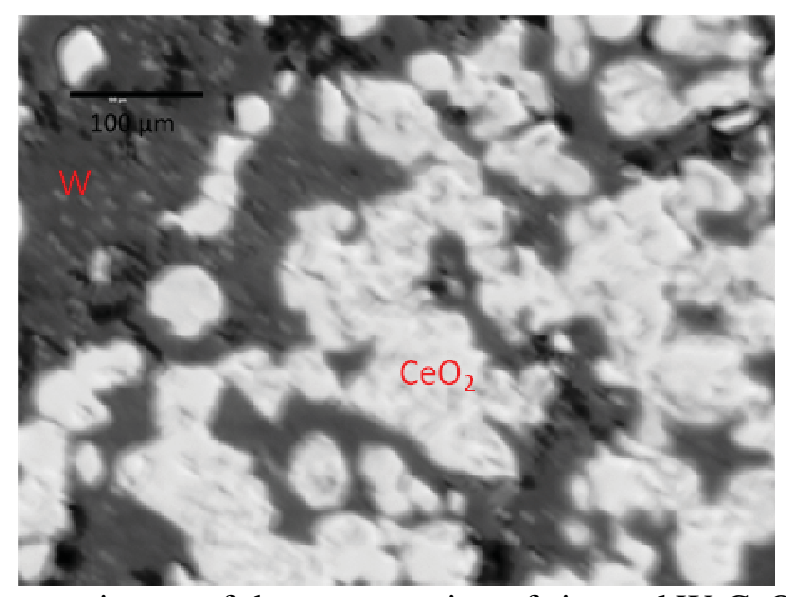

Figure 4. The optical microscope image of the cross section of sintered $\mathrm{W}-\mathrm{CeO}_{2}$ after surface finishing.

Three different cermets are fabricated using SPS via pressure profiles 1, 2 and 3. Figure 4 shows the micrograph of the $\mathrm{W}-\mathrm{CeO}_{2}$ cermets using pressure profile 3 after surface finishing. The white grains are indentified to be $\mathrm{CeO}_{2}$ and black grains are indentified to be $\mathrm{W}$. The reasons are elaborated as below. (i) As Figure 3 shows the tungsten have grain sizes around $10 \mu \mathrm{m}$, indicating little or no grain growth during the SPS process. (ii) The white grains have the size around $50 \mu \mathrm{m}$, which are much larger than the original grain size of tungsten $(10 \mu \mathrm{m})$ but similar with the grain size of $\mathrm{CeO}_{2}(50 \mu \mathrm{m})$. Hence, the white grains are identified as $\mathrm{CeO}_{2}$. It is observed that most $\mathrm{CeO}_{2}$ grains are surrounded by $\mathrm{W}$ grains and the $\mathrm{W}$ grains are connected continuously, suggesting that the $\mathrm{CeO}_{2}$ is encapsulated in the $\mathrm{W}$ matrix. This structure may be applicable for nuclear fuels because the $\mathrm{W}$ metal matrix will serve as the heat conduction channel to conduct the heat produced by the $\mathrm{UO}_{2}$ fuel. The density of the sample is found to be $92 \%$ based on the image analysis. Overall, it is clearly found that with the temperature and pressure considered $\mathrm{W}-\mathrm{CeO}_{2}$ cermets can be produced with high density and proper microstructure. 
The densities and the hardness values of the $\mathrm{W}-\mathrm{CeO}_{2}$ cermets sintered under different pressures are shown in Figure 5(a). It can be clearly seen that both the relative densities and the hardness values of the cermets will increase with the applied external pressures during the SPS process. The density increase is believed to be the result of the enhanced mass transport at higher pressures. It is generally known that the hardness value will increase with increased density. Hence, it is reasonable to see the simultaneous increase of hardness and density. The displacement curves for the SPS process of the $\mathrm{W}-\mathrm{CeO}_{2}$ under different pressures are shown in Figure 5(b). The negative values indicate the thermal expansion during the sintering process, while the positive values indicate the shrinkage due to densification. It is clearly seen that the temperatures for the local minimum points of the curves decrease with the increased pressures. The local minimum points represent the points when shrinkage starts to dominate the displacement curves over the thermal expansion. This trend indicates that higher pressures can lead to the coalescence and/or necking at lower temperatures and hence increase the sintering kinetics in the initial stage. Overall, it is found that higher applied pressures can enhance the effective sintering kinetics, increase the cermets densities and improve the mechanical property (hardness).
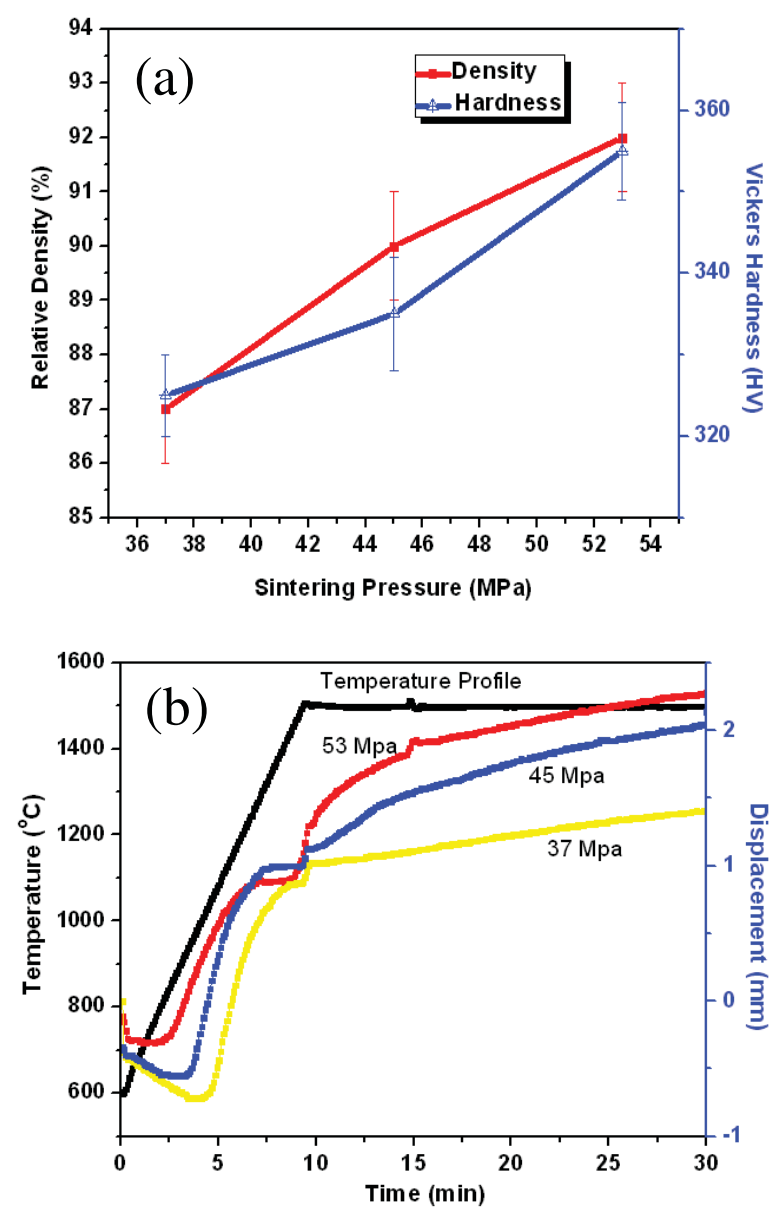

Figure 5. (a) The relative densities and hardness values and (b) the displacement curves during the sintering process for $\mathrm{W}-\mathrm{CeO}_{2}$ cermets sintered under different pressures. 


\section{CONCLUSIONS}

This study demonstrates the feasibility of the fabrication of nuclear fuel cermets using Spark Plasma Sintering process. W-CeO ${ }_{2}$ cermets with densities higher than $90 \%$ may be produced at low sintering temperatures $\left(1500{ }^{\circ} \mathrm{C}\right)$ with a short hold time $(20 \mathrm{~min})$. The microstructures of the cermets show that the ceramic grains are surrounded by a continuous metal phase and porosity remains located at grain boundaries. Higher applied external pressures can lead to higher densities and better mechanical properties.

\section{ACKNOWLEDGMENTS}

The authors Y.Z., K.S., L.S. and J.H. are in debt with the 2011 summer fellowship program of Center for Space Nuclear Research.

\section{REFERENCES}

1. U.S Energy Information Administration, Annual Energy Review (2011).

2. D. E. Burkes, D.M. Wachs, J.E. Warner and S.D. Howe, Proceedings of Space Nuclear Conference 2007, Paper \# 2027 (2007).

3. X. Wang, Y. Xie, H. Guo and O. Van der Biest, Rare Metals 25246 (2006).

4. R.C. O'Brien, R.M. Ambrosi, N.P. Bannister, S.D. Howe and H.V. Atkinson, Journal of Nuclear Materials, 393108 (2009).

5. M.Rosinski, E. Fortuna, A. Michalski, Z. Pakiela, K.J. Kurzydlowski, Fus. Eng. Des. 82 2621 (2007).

6. J. Zhang, L. Wang, W. Jiang, L. Chen, Mater. Sci. Eng. A 487137 (2008)

7. N.C. Kothari, Journal of Less-Common Metals 5140 (1963). 